\title{
The adipocyte fatty acid-binding protein aP2 is required in allergic airway inflammation
}

\author{
Bennett O.V. Shum, ${ }^{1,2,3}$ Charles R. Mackay, ${ }^{1,2,3}$ Cem Z. Gorgun, ${ }^{4}$ Melinda J. Frost, ${ }^{1,2}$ \\ Rakesh K. Kumar, ${ }^{5}$ Gökhan S. Hotamisligil, 4 and Michael S. Rolph 1,2,3
}

\begin{abstract}
${ }^{1}$ Immunology and Inflammation Research Program, Garvan Institute of Medical Research, Darlinghurst, New South Wales, Australia. ${ }^{2} \mathrm{Cooperative} \mathrm{Research}$ Centre for Asthma and Airways, Camperdown, New South Wales, Australia. ${ }^{3}$ St. Vincent's Clinical School, Faculty of Medicine, University of New South Wales, Sydney, New South Wales, Australia. ${ }^{4}$ Division of Biological Sciences and Department of Genetics and Complex Diseases, Harvard School of Public Health, Boston, Massachusetts, USA. ${ }^{5}$ School of Medical Sciences, Faculty of Medicine, University of New South Wales, Sydney, New South Wales, Australia.
\end{abstract}

\begin{abstract}
The adipocyte fatty acid-binding protein aP2 regulates systemic glucose and lipid metabolism. We report that aP2, in addition to being abundantly expressed by adipocytes, is also expressed by human airway epithelial cells and shows a striking upregulation following stimulation of epithelial cells with the Th2 cytokines IL-4 and IL-13. Regulation of $a P 2$ mRNA expression by Th2 cytokines was highly dependent on STAT6, a transcription factor with a major regulatory role in allergic inflammation. We examined aP2-deficient mice in a model of allergic airway inflammation and found that infiltration of leukocytes, especially eosinophils, into the airways was highly dependent on aP2 function. T cell priming was unaffected by aP2 deficiency, suggesting that aP2 was acting locally within the lung, and analysis of bone marrow chimeras implicated non-hematopoietic cells, most likely bronchial epithelial cells, as the site of action of aP2 in allergic airway inflammation. Thus, aP2 regulates allergic airway inflammation and may provide a link between fatty acid metabolism and asthma.
\end{abstract}

\section{Introduction}

Asthma is a chronic inflammatory disease characterized by airway hyperresponsiveness, tissue remodeling, and airflow obstruction (1). The underlying pathogenetic mechanisms in asthma are only partly understood, a situation reflected in the variable and incomplete responses by patients to current therapeutics. The incidence of asthma in Western countries has increased markedly over the last 20 years, and in countries such as the USA and Australia, it now affects approximately $10 \%$ of the population $(2,3)$. Environmental factors must be largely responsible for this sudden increase in incidence. Current thinking is dominated by the hygiene hypothesis, according to which childhood microbial infection is a major determinant of predisposition to atopic asthma (4). Numerous additional environmental factors, such as diet, airborne pollution, and composition of gut commensal microflora are likely involved (5), and further hypotheses that account for the dramatic increase in asthma incidence are required.

Most cases of asthma are associated with characteristic airway immunopathology involving Th2 lymphocytes, eosinophils, mast cells, and goblet cell hyperplasia. The Th2 cytokines IL-4, IL-5, IL-9, and IL-13 initiate and promote asthma pathogenesis (1). IL-4 drives Th2 lymphocyte polarization and also induces IgE class switching. Its importance is highlighted by the attenuated allergic airway phenotype in IL-4-deficient mice (6). IL-5 regulates eosinophil responses by promoting eosinophil differentiation, activation, and survival. In addition to regulating allergic leukocyte responses, Th2 cytokines can directly affect lung parenchymal cells. For example, IL-13 signaling in airway epithelial cells (AECs) mediates airway hyperreactivity and induces airway mucus production (7). Both IL-4 and IL-13 also induce broad phenotypic changes in airway smooth muscle cells (8).

Nonstandard abbreviations used: AEC, airway epithelial cell; BAL, bronchoalveolar lavage; FABP, fatty acid-binding protein; HBE, human bronchial epithelial cell; 5-LO, 5-lipoxygenase; MCP-1, monocyte chemoattractant protein-1.

Conflict of interest: The authors have declared that no conflict of interest exists. Citation for this article: J. Clin. Invest. 116:2183-2192 (2006). doi:10.1172/JCI24767.
The bronchial epithelium is a crucial barrier to the external environment, providing defense against inhaled particles such as allergens and playing a vital role in asthma pathophysiology by regulating such diverse processes as airway remodeling and mucus production (9). Airway epithelial stimulation by IL-4 and IL-13 results in upregulation of adhesion molecules and chemokines such as eotaxin and monocyte chemoattractant protein-1 (MCP-1) that recruit allergic leukocytes to the airways (10-14). However, the contribution of AECs to allergic airway inflammation and the molecular pathways that regulate epithelial cell responses are yet to be fully understood.

Our laboratory has applied gene profiling to the discovery of novel genes regulating inflammatory disease (15-18). To identify potential allergic regulatory and effector pathways in bronchial epithelium, we generated a gene expression profile of human bronchial epithelial cells (HBEs) upon stimulation with the Th2 cytokine IL-4. Here we present evidence that the adipocyte/macrophage fatty acid-binding protein (FABP) aP2 is expressed in HBEs and is strongly upregulated by both IL-4 and IL-13. Using a mouse model of allergic airway inflammation, we demonstrate a key role for aP2 in regulating eosinophil recruitment and pulmonary inflammatory cytokine production. These results suggest that in addition to its role in type 2 diabetes and atherosclerosis (19-21), aP2 may play an essential role in allergic airway diseases such as asthma and offers an additional intriguing link between the immune and metabolic systems.

\section{Results}

IL-4 and IL-13 upregulate aP2 expression in HBEs. To identify new pathways and factors involved in the pathogenesis of asthma, we developed a gene expression profile of HBEs stimulated with the Th2 cytokine IL-4 and found a subset of 38 genes to be IL-4 responsive (Supplemental Figure 1; supplemental material available online with this article; doi:10.1172/JCI24767DS1). Surprisingly, the transcript for the FABP $a P 2$ was one of the most highly regulated genes in response to IL-4 treatment (Figure 1). aP2 is the predominant 


\begin{tabular}{|c|c|}
\hline Gene & $\begin{array}{c}\text { Entrez } \\
\text { transcript ID }\end{array}$ \\
\hline TNFAIP6 & NM_007115 \\
\hline CCL26 & NM 006072 \\
\hline SERPINB4 & NM_002974 \\
\hline$a P 2$ & NM_001442 \\
\hline CAPN14 & XM_496548 \\
\hline TMEM71 & NM_144649 \\
\hline RASGRP1 & NM_005739 \\
\hline SERPINB13 & NM_012397 \\
\hline SLC7A2 & NM_001008539 \\
\hline IL13RA2 & NM 000640 \\
\hline SERPINB3 & NM_006919 \\
\hline TNC & NM_002160 \\
\hline PDZK1IP1 & NM_005764 \\
\hline KAL1 & NM_000216 \\
\hline CXCL6 & NM_002993 \\
\hline PMP22 & NM_000304 \\
\hline NTRK1 & NM_001007792 \\
\hline EST & AW664012 \\
\hline LRRC31 & NM_024727 \\
\hline CTSC & NM_001814 \\
\hline
\end{tabular}

\section{Signal}

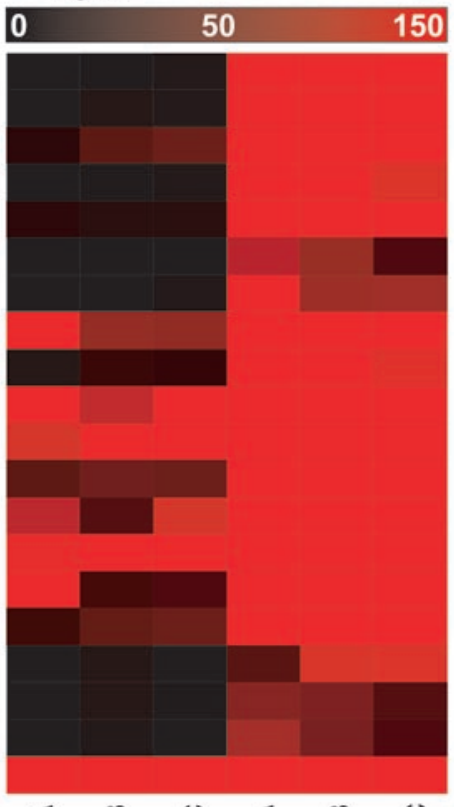

Fold change

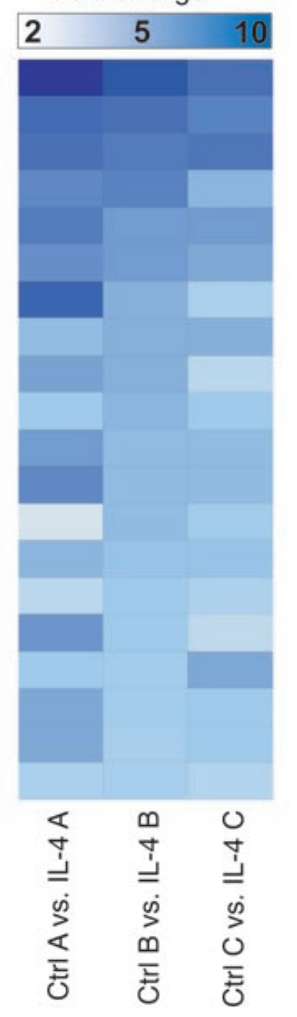

Figure 1

Identification of IL-4-responsive genes in HBE. Transcriptional profiling of HBEs following stimulation with IL-4 was performed using microarray. Signal intensity and fold change of the 20 most highly upregulated genes common to 3 experiments (A, B, and C) are shown. Genes are listed in decreasing order of maximal fold change.
FABP in adipocytes and has a proposed role in intracellular fatty acid transport trafficking $(22,23)$. Although aP2 was originally considered to be adipocyte specific, it has also recently been identified in activated macrophages, where it regulates cholesterol metabolism and cytokine production $(20,24)$. According to real-time PCR, IL-4 and another key Th2 cytokine, IL-13, enhanced aP2 mRNA expression in HBEs as quickly as 1 hour, with maximal expression detected at 12-48 hours (Figure 2A). aP2 was also expressed and was upregulated by IL-4 and IL-13 in the immortalized AEC lines BEAS-2B and A549 (Figure 2B). Enhanced HBE aP2 protein expression following IL-4 or IL-13 stimulation was also observed by immunocytochemistry (Figure 2C). The related FABP mal1, which is thought to have overlapping functions with aP2 (25), was also modestly upregulated by IL-4 or IL-13 in HBEs (Figure 2A). The array data also showed that no other members of the FABP family were expressed by HBEs (data not shown).

Contrasting regulation of aP2 expression in $\mathrm{HBEs}$ and adipocytes. In adipocytes and macrophages, $a P 2$ expression is regulated by PPAR $\gamma$ $(26,27)$. Interestingly, in HBEs, the synthetic PPAR $\gamma$ agonist rosiglitazone had no effect on aP2 mRNA expression (Figure 3A), although it strongly upregulated expression of the PPAR $\gamma$-responsive gene CD36 (Figure 3B) $(28,29)$. In contrast to HBEs, rosiglitazone strongly induced $a P 2$ expression in $3 \mathrm{~T} 3-\mathrm{L} 1$ preadipocytes, while treatment with IL-4 had no effect (Figure 3A), thus highlighting fundamental differences between HBEs and 3T3-L1 cells in the regulation of $a P 2$ expression. Furthermore, HBEs express comparable levels of $a P 2$ to THP-1 monocytes but have approximately 10,000-fold less $a P 2$ mRNA than human adipose tissue (Figure 3C), suggesting that the function of FABPs in bronchial epithelium might differ from that in adipocytes. The fact that different signaling pathways regulate $a P 2$ expression in cytokine-stimulated HBEs and differentiating adipocytes along with the marked differences in expression levels in these cell types suggest that aP2 functions differently in the metabolic and immune systems.

aP2 is a STAT6-regulated gene in HBEs. To further investigate signaling pathways leading to $a P 2$ expression in AECs, we investigated the importance of the transcription factor STAT6. This transcription factor is crucial to IL-4 and IL-13 signaling and binds to the promoter of genes important in allergic responses, such as IL-4 receptor $\alpha$ and eotaxin (30-32). Bioinformatics analysis of sequence upstream of the $5^{\prime}$ transcriptional start site in mouse and human genomic aP2 sequences revealed a conserved putative STAT6-binding site at positions -383 and -396 , respectively (Supplemental Figure 2A). Since STAT6 signaling is activated by IL-4 in AECs (33) (Supplemental Figure 2B), we focused on this signaling element as a potential regulator of $a P 2$ expression. We initially used overexpression studies to confirm the importance of STAT6. Transfection of BEAS-2B AECs with a plasmid encoding WT STAT6 increased aP2 expression 2.1-fold over that of control transfectants, and expression of a constitutively active STAT6 mutant significantly upregulated $a P 2$ expression 6.1-fold (Figure 3D). Conversely, aP2 upregulation by IL-4 was blocked in transfectants expressing a dominant negative STAT6 isoform (Figure 3E). In WT primary mouse AECs, aP2 expression was increased by treatment with IL-4 plus TNF- $\alpha$ (Figure 3F), but it was unchanged in AECs from STAT6-deficient mice (Figure 3G). Taken together, these studies confirm that IL-4-mediated STAT6 signal transduction in AECs leads to downstream aP2 gene expression and that STAT6 activation alone is sufficient to increase $a P 2$ gene transcription.

The Th1 cytokine IFN- $\gamma$ downregulates aP2 expression. Given the strong regulation of $a P 2$ expression by Th2-related cytokines, we next tested a range of other cytokines and factors known to affect 
A

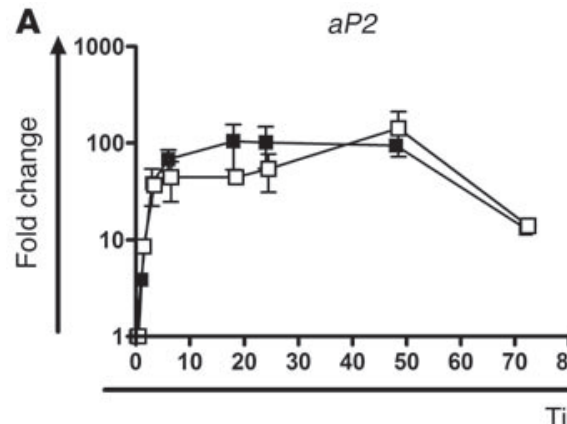

B

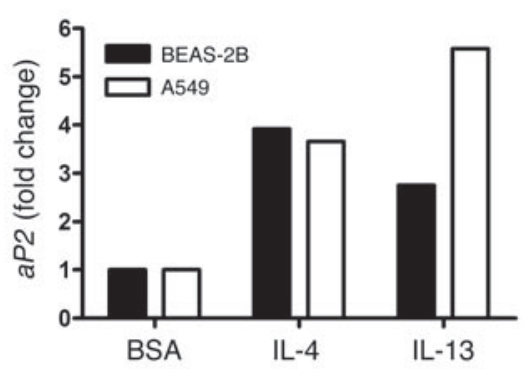

mal1

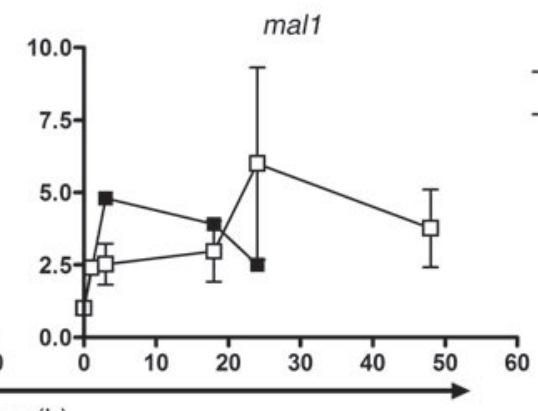

Time (h)
C

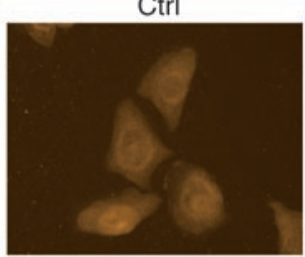

IL-13

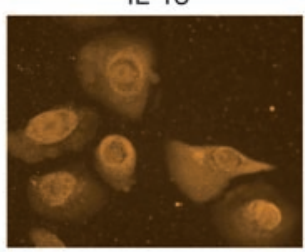

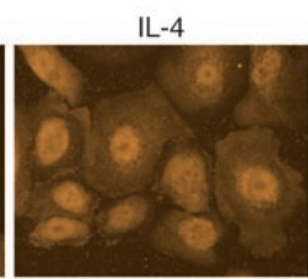

Isotype ctr|

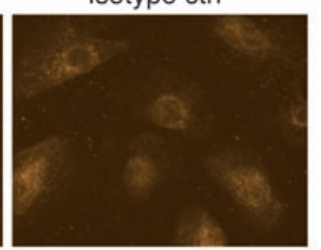

\section{Figure 2}

Regulation of aP2 expression in HBEs is enhanced by IL-4 and IL-13. (A) Time course of aP2 induction in HBEs after 1, 3, 6 , $12,18,24,48$, and 72 hours or of mal1 induction after $3,6,18$, 24 , and 48 hours, using real-time PCR activation after treatment with IL-4 or IL-13. Data represent mean \pm SEM of 3 experiments. The data for the one-hour time point represent the mean of duplicate experiments. (B) BEAS-2B and $A 549$ cells were treated with IL-4 or IL-13 for 18 hours and aP2 expression assayed by real-time PCR. (C) HBEs were stimulated with BSA (Ctrl), IL-4, or IL-13 for 24 hours and stained with antiaP2 or isotype control antibodies with immunofluorescence. Images are representative of 3 experiments. Original magnification, $\times 400$. bronchial epithelial cell function. In contrast to IL-13 or IL-4, IFN- $\gamma$ downregulated aP2 expression, while IL-1, IL-3, IL-6, IL-9, MCP-1, TNF- $\alpha$, or IL-10 had no effect (Figure 4A). Whereas IL-4 and IL-13 exacerbate allergic airway inflammation, the prototypic Th1 cytokine IFN- $\gamma$ is, in some cases, protective against allergy by antagonizing Th2 effector function $(34,35)$. Thus, upregulation by Th 2 cytokines and downregulation by Th1 cytokines strongly implicate aP2 as a participant in allergic airway inflammation.

Preferential expression of aP2 in allergic tissues. To more rigorously investigate the potential role of aP2 in regulating airway inflammation, we used a mouse model of allergic airway inflammation. We investigated whether aP2 is expressed in airway epithelium of mice with pulmonary allergic inflammation. In lungs from nonallergic control mice, a low level of aP2 staining was observed in AECs (Figure 4B). In mice with allergic airway inflammation, aP2 staining intensity in the AECs was noticeably increased. In lungs from both the nonallergic and allergic groups, aP2 staining was observed almost exclusively in the AECs, although occasional isolated cells within the lung, which may be macrophages or DCs (refs. 20, 27, and Rolph et al., manuscript submitted for publication), were also stained. Very strong aP2 staining was also detected in human turbinate tissue (Supplemental Figure 3) and nasal polyps (data not shown), although there was no correlation between staining intensity and degree of inflammation. Thus, aP2 is regulated at both the transcript and protein levels, in epithelial cell lines as well as bronchial epithelium in vivo.

Regulation of allergic airway inflammation by aP2. We next tested the role of aP2 in allergic airway inflammation by utilizing aP2 $2^{-/-}$mice. After OVA sensitization and aeroallergen challenge, a significant increase in total cell number was observed in the bronchoalveolar lavage (BAL) fluid of WT $\left(a P 2^{+/+}\right)$mice (Figure 5A). The cellular infiltrate was composed largely of eosinophils (Figure 5B), as is typical for this model. In contrast, the total number of BAL leukocytes was significantly decreased in $\mathrm{aP} 2^{-/-}$mice (Figure 5A), and this was associated with reductions in the number of eosinophils and neutrophils (Figure 5B). Lung histology also revealed a significantly reduced peribronchial and perivascular inflammatory infiltrate in allergic $a P 2^{-/-}$mice, compared with allergic $a P 2^{+/+}$controls (Figure 5C, upper panels) ( $P<0.01$, Mann-Whitney $U$ test). However, mucus overproduction in allergic mice was unaffected by aP2 deficiency (Figure 5C, lower panels).

To further understand the role of aP2 in allergic airway inflammation, we measured cytokine levels in the BAL fluid. In accordance with the marked attenuation in airway eosinophilia, aP2-/mice had significantly less IL-5 and IL-13 in BAL fluid, while a trend toward lower eotaxin levels was observed (Figure 6A). Similarly, in comparison to $\mathrm{aP} 2^{+/+}$mice, we detected a significant reduction in IL-5 production by OVA-stimulated cells from the draining lymph nodes of $a 2^{-/-}$mice (Figure $6 \mathrm{~B}$ ). Gene profiling of lung tissue from allergic $a P 2^{+/+}$and $a P 2^{-/-}$mice also revealed a broad reduction in many genes already implicated in Th2 inflammation, such as the chemokines eotaxin-1 and -2, MCP-1, and matrix metalloproteinases $M M P-12$ and -9 and arginase $I(15,36,37)$ in aP2 $2^{-/-}$mice (Supplemental Figure 5) (38).

Antigen-specific $T$ cell proliferation is unimpaired in aP2 $2^{-/-}$mice. A logical assumption based on the above findings is that aP2 deficiency in AECs might compromise airway Th2 responses. To exclude the possibility that the initial $T$ cell priming contributed to the phenotype of the $a 2^{-/-}$mice in the allergic airway inflammation model, mice were immunized with OVA in alum, and antigen specific-responses in the spleen were measured. OVAspecific proliferation (Figure 6C) and production of IL-5 and IFN- $\gamma$ in supernatants (unpublished observations) were equivalent from WT and $a P 2^{-/-}$spleen cells. Thus, T cell priming in the 
A
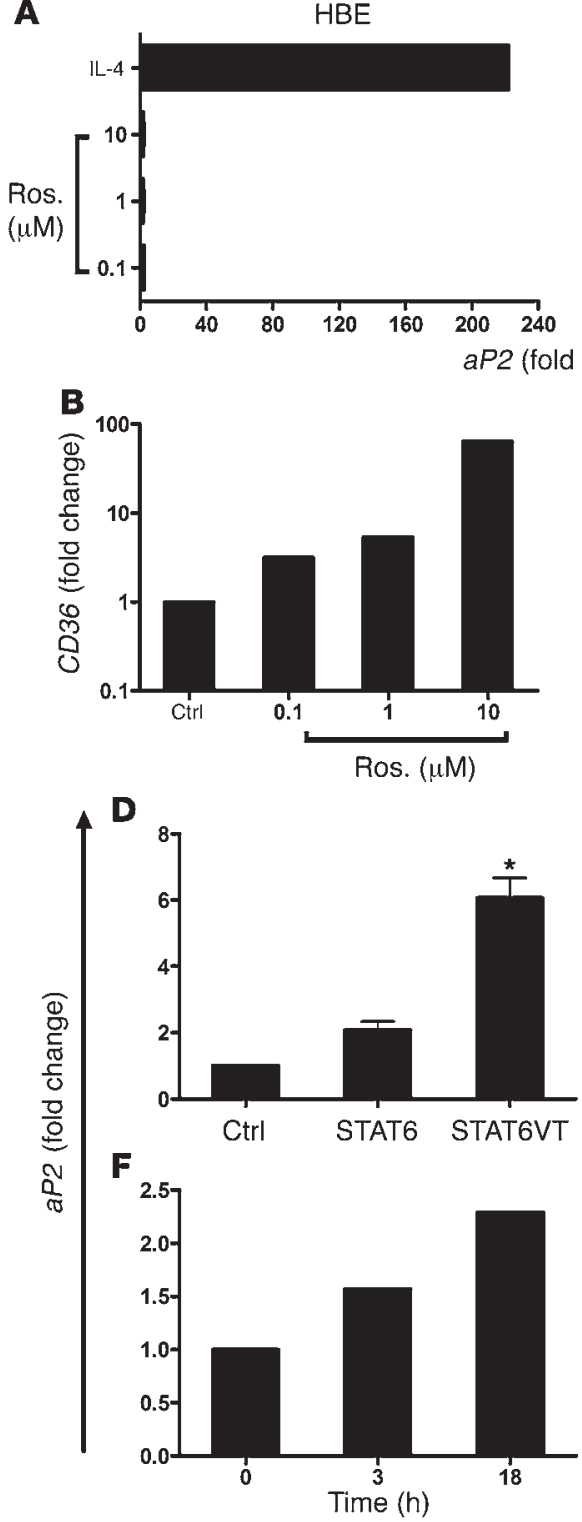

3T3-L1
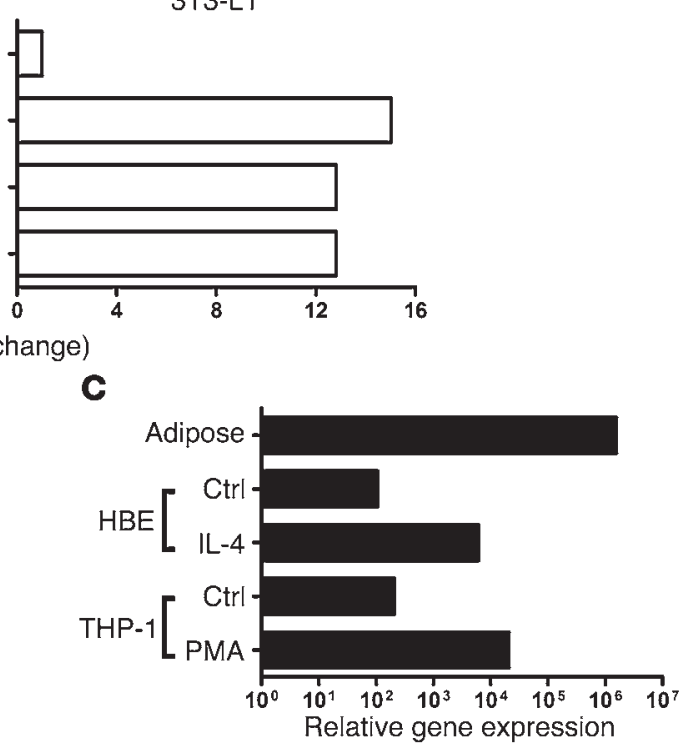

E

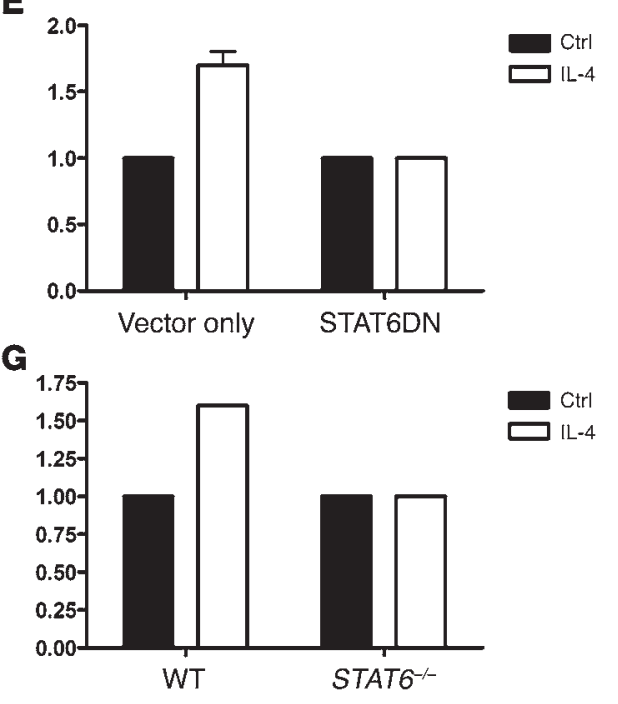

Figure 3

Differential expression and regulation of $a P 2$ expression by PPAR $\gamma$ activation in HBEs and adipocytes. (A) HBEs and 3T3-L1 preadipocytes were treated with rosiglitazone (Ros.) or vehicle control and aP2 mRNA expression assessed. Data represent mean of 3 HBE and two 3T3-L1 experiments. (B) CD36 message levels were determined in HBEs after rosiglitazone treatment. Data represent mean of 2 experiments. (C) Relative abundance of $a P 2$ message from 100 ng RNA was compared among human adipose tissue, HBEs, HBEs plus IL-4, THP-1 monocytes, and THP-1 monocytes plus PMA. (D) Transient transfection of BEAS-2B cells with WT STAT6, constitutively active STAT6 mutant (STAT6VT), or empty vector plasmids for 72 hours. aP2 expression was monitored by real-time PCR. Data represent mean \pm SEM of 3 experiments. ${ }^{*} P<0.05$ compared with vector control. (E) Transient transfection of BEAS-2B cells with STAT6 dominant negative (STAT6DN) or empty vector plasmids. Twenty-four hours after transfection, cells were treated with IL-4 for 18 hours, and $a P 2$ transcript was quantified. Data represent mean \pm SEM of 4 experiments. (F) Time course of aP2 expression in WT AECs after 3 or 18 hours treatment with IL-4 and TNF- $\alpha$. Data represent the mean results from 2 independent cultures. (G) STAT6-deficient AECs were cultured in vitro and treated with IL-4 for 18 hours, and $a P 2$ mRNA expression was assessed. Data represent the mean results of 2 independent cultures.

allergic airway inflammation model was not noticeably affected by aP2 deficiency, suggesting that the defect is likely to be mediated locally within the lung.
Non-hematopoietic cells regulate allergic lung inflammation in aP2 $2^{-1-}$ mice. To more rigorously test whether hematopoietic or non-hematopoietic cells were responsible for ameliorated lung inflammation in aP2-deficient mice, bone marrow transfer experiments were conducted. WT and $a P 2^{-1-}$ mice were lethally irradiated and reconstituted with WT or $a P 2^{-/-}$bone marrow to generate $\mathrm{WT} \rightarrow \mathrm{WT}, a 2^{-\prime-} \rightarrow \mathrm{WT}$, and WT $\rightarrow a 2^{-/-}$chimeric mice. The mice were then sensitized to OVA and challenged with aerosolized OVA to induce allergic lung inflammation. After antigen challenge, $\mathrm{WT} \rightarrow \mathrm{WT}$ and $a P 2^{-/} \rightarrow$ WT mice had similar total numbers of leukocytes infiltrating the airway lumen, whereas $a P 2^{-/-}$mice that received WT bone marrow had significantly fewer leukocytes (Figure 7A). Differential cell counts of lavaged cells revealed a significant reduction in the number of eosinophils from WT $\rightarrow a P 2^{-/-}$ chimeras compared with WT $\rightarrow$ WT and $a P 2^{-\mu} \rightarrow$ WT animals, while monocyte/macrophage numbers remained unchanged (Figure 7B). Allergic cytokine levels were also altered in allergic aP2-knockout mice with WT immune cells. In these mice, eotaxin and IL-5 levels were significantly decreased in lung lavage fluid (Figure 7C), while IL-5 and IL-13 levels were significantly reduced in culture supernatants from lung-draining lymph node cells restimulated with OVA antigen (Figure 7, $\mathrm{D}$ and $\mathrm{E})$. These results clearly indicate that non-hematopoietic cells are the site of action of aP2 in allergic airway inflammation.

The expression of aP2, and its regulation by IL- 4 and IL-13, in AECs strongly suggests that these cells are the site of action of aP2. To obtain further evidence in support of this, the response of aP2-deficient mice was tested in a model of allergic inflammation independent of AECs. Mice were sensitized to OVA in alum by 2 subcutaneous injections, followed by intraperitoneal OVA challenge. Twentyfour hours following OVA challenge, this protocol induced a 
A

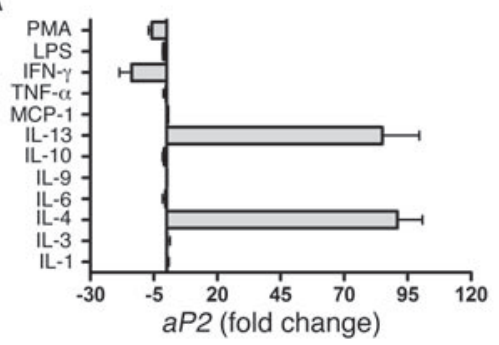

\section{Figure 4}

Evidence for the role of aP2 in Th2-mediated airway inflammation (A) HBEs were treated with a panel of cytokines and stimuli and $\mathrm{AP} 2$ expression assessed with real-time PCR. Data represent mean \pm SEM of 3 experiments for IL-4, IL-13, and IFN- $\gamma$; 1 experiment for IL- 9 and MCP-1; and 2 experiments for the other treatments. (B) BALB/c mice in which allergic lung inflammation was induced or control mice were immunostained for aP2: brown, positive aP2 staining; blue, nuclei. Images are representative of 3 mice per condition. Original magnification, $\times 400$.

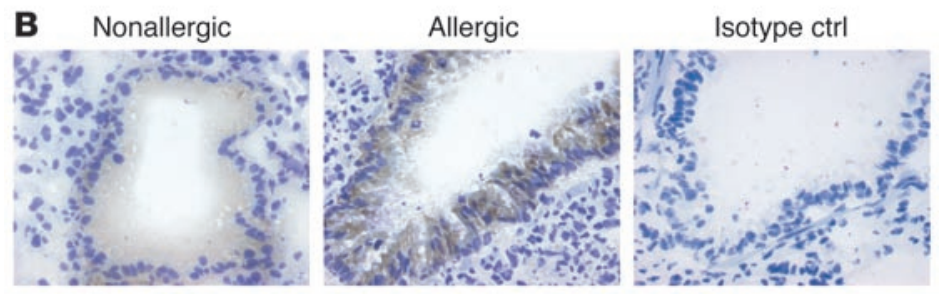

localized peritoneal allergic inflammation, with substantial influx of multiple leukocyte subsets, particularly eosinophils and macrophages, into the peritoneal cavity. There was no difference between WT and $a 2^{-/-}$mice in the magnitude and nature of the inflammatory infiltrate (Figure $8, \mathrm{~A}$ and $\mathrm{B}$ ). These results indicate there is not a general defect in allergic responses in the $a 2^{-/-}$mice and give further support to our proposal that the airway epithelium is the site of action of aP2 in allergic airway inflammation.

\section{Discussion}

Lipids have diverse and complex cellular functions, acting as membrane phospholipid constituents, metabolic substrates, precursors for signaling molecules, and mediators of gene expression. Highly complex molecular pathways are required to regulate these activities and maintain intra- and extracellular lipid homeostasis. FABPs are considered to play a critical role in lipid homeostasis, although their precise molecular mode(s) of action are incompletely understood. The adipocyte FABP, aP2, has long been utilized as a specific adipocyte marker and has recently also been identified in macrophages (39). aP2 is thought to regulate fatty acid uptake, release, and storage in adipocytes and participates in systemic glucose homeostasis and in macrophage responses in atherosclerosis $(20,40)$. Our findings now identify aP2 as an IL-4/IL-13-regulated gene in bronchial epithelial cells and demonstrate a key role for this FABP in Th2 cytokine-mediated airway inflammation.

The factors regulating $a P 2$ expression have been widely studied in adipocytes, particularly during adipocyte differentiation. In adipocytes, aP2 expression is controlled predominantly by fatty acids and particularly by PPAR $\gamma$ agonists (41). Despite the fact that they have a functional PPAR $\gamma$ signaling pathway, we found no evidence

\section{Figure 5}

aP2 deficiency ameliorates allergic lung inflammation and airway eosinophilia. WT or aP2 $2^{-/-}$mice were sensitized and challenged with OVA for airway inflammation (Allergic) or with PBS as a control (Nonallergic). Total (A) and differential (B) cell counts from BAL. E, eosinophil; M, monocyte/macrophage; L, lymphocyte; N, neutrophil. Data represent mean values \pm SEM for $n=10$ nonallergic and $n=12-15$ allergic WT or $\mathrm{aP}^{-/-}$mice from 2 experiments. ${ }^{*} P<0.05$, ${ }^{*} P<0.0005$ compared with WT. (C) Histological examination of lungs stained with H\&E (upper panel; original magnification, $\times 100$ ) or Alcian blue-PAS (lower panel; original magnification, $\times 400$ ) for mucus. Magenta staining is indicative of mucus.

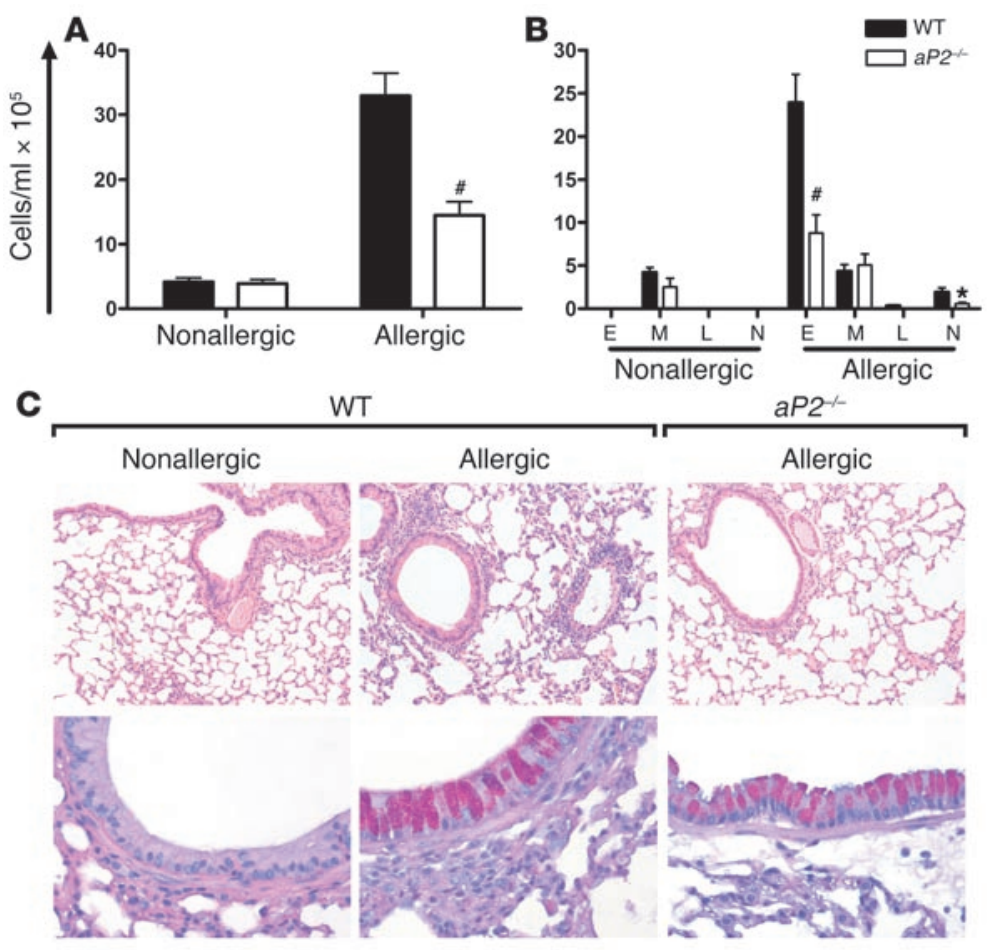



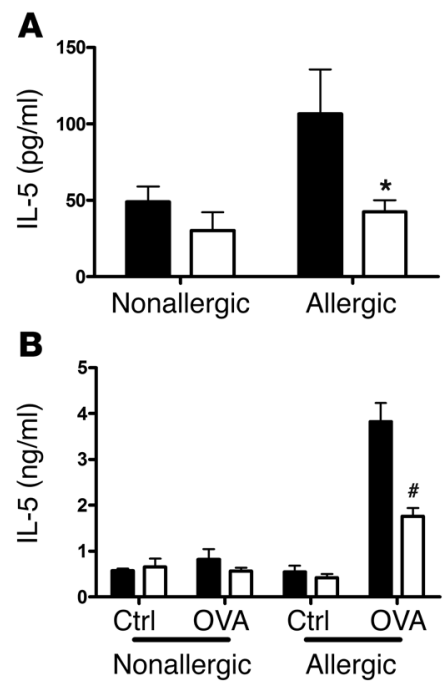
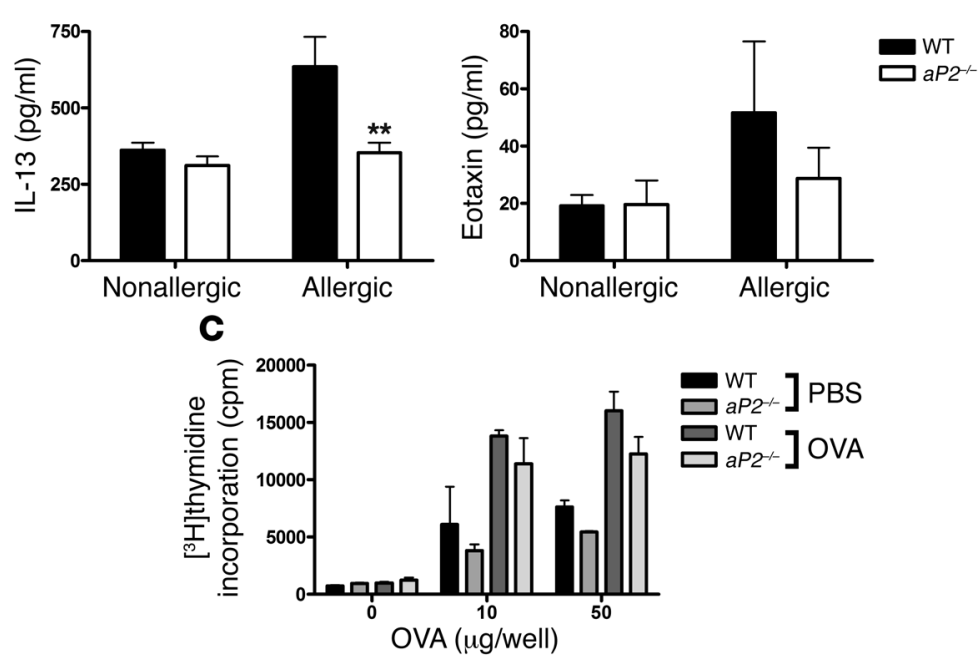

\section{Figure 6}

Allergic cytokine production is decreased in allergic aP2-deficient mice. (A) Detection of IL-5, IL-13, and eotaxin in BAL fluid from nonallergic $(n=10)$ and allergic $(n=12-15)$ aP2+/+ or aP2-/- mice. Data represent mean values \pm SEM. ${ }^{*} P<0.05 ;{ }^{* *} P<0.005$. (B) IL-5 was measured in culture supernatants from lung-draining lymph node cells restimulated in vitro with OVA or PBS only (Ctrl). Data represent mean \pm SEM of 3-4 cultures in triplicate wells with cells pooled from 3-4 mice per culture. $\# P<0.0005$. (C) Unimpaired T cell proliferation in $a P 2^{-1-}$ mice. Splenocytes from OVA/alum-immunized or PBS/alum control mice were stimulated with OVA antigen in vitro and cellular proliferation assayed. Data represent mean \pm SEM of triplicate wells with 5 and 2 mice per genotype for OVA/alum and PBS/alum groups, respectively.

for PPAR $\gamma$-mediated regulation of $a P 2$ expression in HBEs. In airway epithelium, STAT6 was shown to be largely responsible for upregulation of $a P 2$ by IL-4. The other major stimulus regulating aP2 expression in HBEs was the type 1 cytokine IFN- $\gamma$, which induced a significant downregulation. Upregulation by Th2 cytokines and downregulation by Th1 cytokines provided a strong indication that aP2 was involved in Th2 inflammation. This was further supported by the observation of increased aP2 expression in AECs of mice undergoing allergic airway inflammation.

The bronchial epithelium plays an active role in the asthmatic inflammatory response. In particular, STAT6-dependent responses to IL-4 and IL-13 in epithelial cells are thought to
Figure 7

Non-hematopoietic cells are responsible for reduced allergic airway inflammation in $\mathrm{aP2} 2^{-/-}$mice. WT or $a P 2^{-I-}(\mathrm{KO})$ bone marrow was transferred into irradiated mice to generate $\mathrm{KO} \rightarrow \mathrm{WT}, \mathrm{WT} \rightarrow \mathrm{KO}$, or WT $\rightarrow \mathrm{WT}$ (donor $\rightarrow$ recipient) chimeras, and their responses to allergic airway inflammation assessed. Total (A) and differential $(B)$ cell counts from BAL of bone marrow chimeric mice. Data represent mean values \pm SEM for $n=13 \mathrm{KO} \rightarrow \mathrm{WT}$ mice, $n=11 \mathrm{WT} \rightarrow \mathrm{KO}$ mice, and $n=6$ $\mathrm{WT} \rightarrow \mathrm{WT}$ mice. ${ }^{\star} P<0.05$ compared with $\mathrm{KO} \rightarrow \mathrm{WT}$ mice. (C) Detection of IL-5 and eotaxin in BAL fluid from allergic chimeric mice. Data represent mean \pm SEM for $n=13 \mathrm{KO} \rightarrow \mathrm{WT}$ mice and $n=11 \mathrm{WT} \rightarrow \mathrm{KO}$ mice. ${ }^{\star} P<0.05 ;{ }^{*} P<0.005$. (D and E) Detection of IL-5 and IL-13 from culture supernatants of allergic chimeric mouse lung-draining lymph node cells restimulated in vitro with OVA. Data represent mean \pm SEM of 3 cultures from cells pooled from 4-5 mice per condition. ND, not detected.
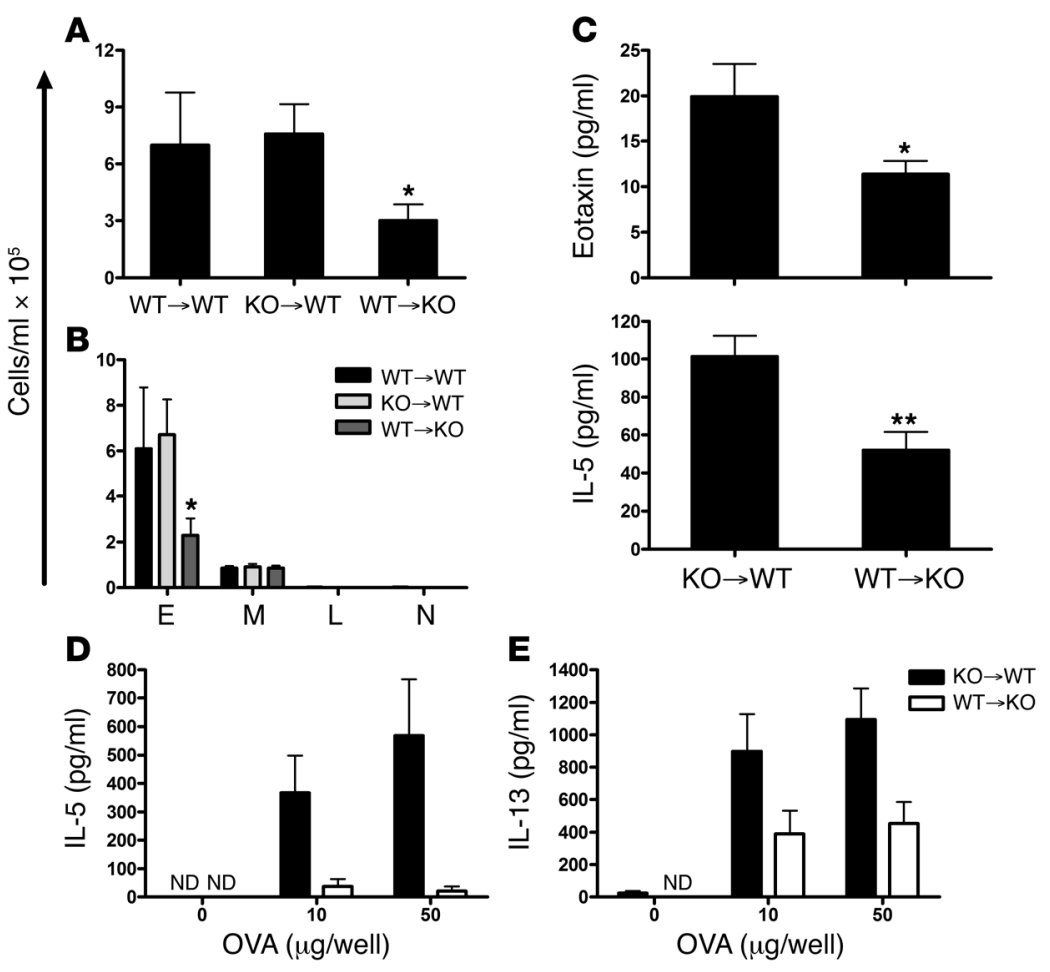

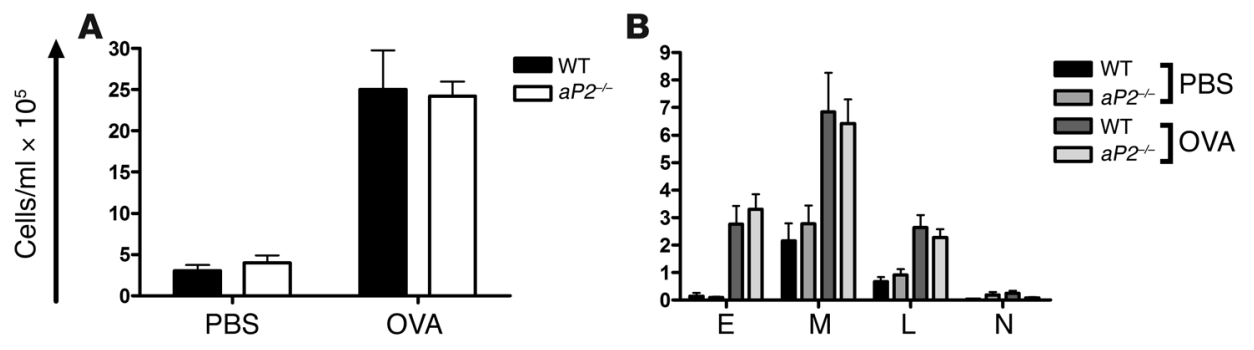

Figure 8

Allergic peritoneal responses are unaltered in $\mathrm{aP} 2^{-/-}$mice. (A) Mice were sensitized and challenged with OVA or PBS as a control. Peritoneal cells were obtained and total cells enumerated. Data represent mean \pm SEM; $n=5$ mice per group. (B) Differential assessment of cells from peritoneal lavages of allergic or control mice. Data represent mean values \pm SEM.

make a major contribution to disease pathogenesis $(9,42,43)$. A number of IL-4/IL-13-responsive, STAT6-dependent genes have been identified in airway epithelium, but in few cases has their contribution to allergic airway inflammation and cellular site of action been defined. The present study clearly identifies aP2 as a STAT6-dependent regulator of allergic airway inflammation, and we have made considerable effort to test whether AECs were the site of aP2 activity. Since aP2 is known to regulate inflammatory responses in macrophages $(20,44)$ and DCs (Rolph et al., manuscript submitted for publication), our studies focused on the potential contribution of these cell types. Using bone marrow chimeras and analyzing $\mathrm{T}$ cell responses in OVAprimed mice, we found no evidence for a contribution of aP2 in hematopoietic cells in allergic airway inflammation. In addition, allergic responses outside of the lung (in the peritoneal cavity) were unimpaired in $\mathrm{aP}^{-{ }^{--}}$mice. Taken together with our in vitro and in vivo airway epithelial expression data, our data strongly suggests that the airway epithelium is the major site of action of aP2 in allergic airway inflammation.

aP2 has been widely studied in adipocytes, where it is thought to facilitate lipid transport and metabolism. In contrast, the role of aP2, and other FABPs, in inflammatory responses has received little attention. Understanding the molecular mechanism by which aP2 regulates allergic airway inflammation is likely to identify new signaling events that regulate inflammatory responses. aP2 has recently been described as a regulator of PPAR $\gamma$ and NF- $\kappa B$ in macrophages $(44,45)$. Both these transcription factors are present in, and regulate inflammatory responses of, AECs. However, a number of other plausible mechanisms are suggested by the ability of aP2 to bind a range of long-chain fatty acids. For example, aP2 binds arachidonic acid and a number of its metabolites (46) and could modulate production or metabolism of bioactive eicosanoids. Indeed, recent studies have demonstrated that aP2 can bind the 5-lipoxygenase (5-LO) product leukotriene $\mathrm{A}_{4}$ (LTA4) and markedly extend its half-life (47). 5-LO participates in a broad range of inflammatory diseases, but it appears to have a particularly strong involvement in asthma and atherosclerosis (48-50). Our data, together with those of Makowski et al. (20), now identify aP2 as an additional pathophysiological link between these 2 diseases. Since aP2 binds and stabilizes the 5-LO product LTA4, this suggests the intriguing possibility of a common pathway in asthma and atherosclerosis involving cooperation between aP2 and 5-LO in eicosanoid biosynthetic pathways, either by direct intracellular interaction or by transcellular biosynthesis (51).
The identification of a FABP that regulates allergic airway inflammation emphasizes the importance of lipids in the inflammatory response, and our findings contribute to the emerging theme of overlap between inflammatory and metabolic pathways (39). aP2 is a member of a larger family of FABPs with distinct patterns of tissue distribution (23). The ability of aP2 to regulate inflammation may thus represent a general feature of FABP biology, implying a role for FABPs in a broad range of inflammatory diseases. Finally, our findings suggest blocking aP2 function as a novel approach for treatment of asthma and other inflammatory lung diseases.

\section{Methods}

Cell culture. Normal HBEs (Cambrex) were maintained in Bronchial Epithelial Growth Media (BEGM), which consisted of Clonetics Bronchial Epithelial Basal Media (BEBM) supplemented with $52 \mathrm{mg} / 1$ bovine pituitary extract, $0.5 \mathrm{mg} / \mathrm{l}$ hydrocortisone, $0.5 \mathrm{mg} / \mathrm{l}$ human recombinant epidermal growth factor, $0.5 \mathrm{mg} / \mathrm{l}$ epinephrine, $10 \mathrm{mg} / \mathrm{l}$ transferrin, $5 \mathrm{mg} / \mathrm{l}$ insulin, $0.1 \mathrm{mg} / \mathrm{l}$ retinoic acid, $6.5 \mathrm{mg} / \mathrm{l}$ triiodothryonine, $50 \mathrm{mg} / \mathrm{l}$ gentamicin, and $50 \mathrm{mg} / \mathrm{l}$ amphotericin B. All media components were from Cambrex. When $80 \%$ confluent, cells were subcultured at a ratio of 1:3 with $0.025 \%$ trypsin-EDTA (Invitrogen). Prior to stimulation, HBEs were rested overnight in BEBM containing 0.1\% low-endotoxin BSA (SigmaAldrich). HBEs were treated for 18 hours for all experiments except where noted and used at no later than passage 8 .

3T3-L1 preadipocytes and A549 and BEAS-2B cells were used at $80 \%$ confluency and maintained in complete DMEM or DMEM/Ham's F-12 (1:1) (Invitrogen). THP-1 cells were cultured in complete RPMI 1640. Complete media were those supplemented with $10 \%$ heat-inactivated FCS, $2 \mathrm{mM}$ glutamine, and $100 \mathrm{U} / \mathrm{ml}$ penicillin/streptomycin and were all purchased from Invitrogen.

Primary mouse AECs from mice 8-12 weeks old were cultured as described previously (52) with the following modifications. Enzymatic dissociation of tracheal cells was performed for 45 minutes, and cells from 2 trachea were cultured in 1 well of a 24-well plate coated with type I collagen (Sigma-Aldrich) in DMEM/Ham's F-12 (1:1) media supplemented with insulin (120 IU/l), 5\% FCS, $2 \mathrm{mM}$ glutamine, and $100 \mathrm{U} / \mathrm{ml}$ penicillin/streptomycin. Cell purity was typically greater than $98 \%$ as assessed by staining cells grown on glass coverslips with anti-cytokeratin antibodies (Sigma-Aldrich). Prior to cytokine treatment, AECs were rested in unsupplemented AEC growth media with $0.1 \%$ BSA overnight.

Overexpression studies. BEAS-2B cells were cultured in T75 flasks (Nunc) and transiently transfected 72 hours with Lipofectamine 2000 (Invitrogen) with $10 \mu \mathrm{g}$ plasmid DNA. Mammalian STAT6 and constitutively active STAT6 (STAT6VT) constructs were a kind gift from H. Nakajima (Chiba University, Chiba, Japan) and dominant negative STAT6 (STAT6DN) plasmid was from A. Masuda (Nagoya University, Nagoya, Japan). For dominant negative studies, cells were transfected 6 hours and media replaced with DMEM with $0.1 \%$ BSA overnight prior to cytokine stimulation.

Reagents. HBEs were treated with the following human recombinant cytokines from BD Biosciences - Pharmingen: IL-3 $(20 \mathrm{ng} / \mathrm{ml})$, IL-4 $(10 \mathrm{ng} / \mathrm{ml})$, IL-6 $(5 \mathrm{ng} / \mathrm{ml})$, IL-10 (10 ng/ml), IL-13 (10 ng/ml), and IFN- $\gamma$ $(100 \mathrm{U} / \mathrm{ml})$; or from PeproTech: IL-1 $(10 \mathrm{ng} / \mathrm{ml}), \mathrm{TNF}-\alpha(10 \mathrm{ng} / \mathrm{ml})$, and 
murine IL-4 (20 ng/ml). PMA and LPS (Sigma-Aldrich) were added for a final concentration of $50 \mathrm{ng} / \mathrm{ml}$ and $100 \mathrm{ng} / \mathrm{ml}$, respectively. Rosiglitazone was purchased from Cayman Chemicals.

RNA extraction and GeneChip bybridizations. Total RNA was isolated from cells using the RNeasy Mini Kit (QIAGEN) or TRIzol (Invitrogen) as per the manufacturer's instructions. Two HBE lines, lot 8F1142 and 7F1482, that originated from white males aged 18 months and 32 years, respectively, were gene profiled using U133plus2 GeneChips (Affymetrix). The full microarray data set is available online at http://gspring.garvan.unsw. edu.au. For mouse experiments, lung RNA was pooled from $n=3 \mathrm{WT}$ and $n=2 \mathrm{aP2} 2^{-/}$animals. cRNA and GeneChips (Affymetrix) were prepared as described previously (53). MicroArray Analysis Suite 5.0 software (Affymetrix) was used to generate "signal to log ratio" values from gene "signal" intensities and from the fold change that was calculated (fold change $=2^{\text {signal to } \log \text { ratio }}$ ). A gene was considered to be differentially regulated with a fold change of at least 2 . Spotfire Inc. software was used to map gene expression patterns.

Real-time PCR. cDNA was made from $100 \mathrm{ng}$ total RNA using Reverse-IT RTase Blend kit (ABgene) or from $2 \mu \mathrm{g}$ total RNA with avian myeloblastosis virus reverse transcriptase (Promega) according to the manufacturer's instructions. Real-time PCR were conducted using a Light Cycler-FastStart DNA Master SYBR Green I kit (Roche Diagnostics) using $2.5 \mathrm{mM}$ $\mathrm{MgCl}_{2}$ and $1 \mu \mathrm{M}$ primers. The reaction mixes were run for 35 cycles at $95^{\circ} \mathrm{C}$ ( 15 seconds), $63^{\circ} \mathrm{C}\left(5\right.$ seconds), and $72^{\circ} \mathrm{C}$ (10 seconds). Primers used to analyze gene expression were designed from GenBank sequences using Primer3 software (54). The following primers were used: human GAPDH, 5'-CACATCAAGGTGGTGAA-3' and 5'-TGTCATACCAGGAAATGAGC-3'; human aP2, 5'-GGCATGGCCAAACCTAACAT-3' and 5'-TTCCATCCCATTTCTGCACAT-3'; human mal1, 5'-GCAATGGCCAAGCCAGATTGT-3' and 5'-CCCATCCCACTCCTGATGCT-3'; human CD36, 5'-GGAAAGTCACTGCGACATGAT-3' and 5'-GCCTTGGATGGAAGAACAAA- $3^{\prime}$; murine $a P 2,5^{\prime}$-GATGCCTTTGTGGGAACCTG- $3^{\prime}$ and $5^{\prime}$-GAATTCCACGCCCAGTTTGA-3'; murine $\beta$-actin, $5^{\prime}$-AGAGGGAAATCGTGCGTGAC3' and 5'-CAATAGTGATGACCTGGCCGT-3'; murine GAPDH, $5^{\prime}$-CTCATGACCACAGTCCATGC-3' and 5'-CACATTGGGGGTAGGAACAC-3'. Gene expression was normalized to GAPDH or $\beta$-actin and expressed as fold change between samples. PCR products were run on a $2 \%$ agarose gel containing $500 \mathrm{ng} / \mathrm{ml}$ ethidium bromide (Sigma-Aldrich) to ensure products were of expected size. The identity of the aP2 amplicon was also confirmed by sequencing at the Sydney University Prince Alfred Macromolecular Analysis Centre.

Anti-aP2 antibody generation. Recombinant histidine/T7-tagged full-length human aP2 protein was expressed in E. coli with a PET28a expression vector (EMD Biosciences) and purified using an Ni-NTA column (QIAGEN) as per the manufacturer's instructions. Mouse anti-aP2 antibodies (clone $6 \mathrm{E} 12, \mathrm{IgG} 2_{\mathrm{a}}$ isotype) were generated by immunizing aP2/mal1 doubledeficient mice with 50 or $25 \mu \mathrm{g}$ histidine-cleaved recombinant protein 4 times, 2 weeks apart, and cell fusion was performed as described previously (55). 6E12 was positive against histidine-cleaved recombinant human aP2 protein, negative against recombinant mal1 protein by ELISA (data not shown), and positive against human and mouse adipose tissue by Western blotting (Supplemental Figure 4).

Immunostaining. aP2 immunostaining was performed with human and mouse cross-reactive anti-aP2 rabbit polyclonal IgG antibodies kindly provided by D. Bernlohr (University of Minnesota, Minneapolis, Minnesota, USA). For HBEs, cells were grown on glass coverslips and, after 24 hours cytokine activation, fixed in $1 \%$ formaldehyde for 20 minutes and permeabilized with $70 \%$ ethanol for 20 minutes at $-20^{\circ} \mathrm{C}$. Cells were then blocked in 10\% normal goat serum (Sigma-Aldrich) diluted in 2\% BSA/TBS for 30 minutes prior to overnight incubation with anti-aP2 antibodies at a
1:1,000 dilution. Detection was performed with biotinylated goat anti-rabbit IgG antibodies (Dako) and avidin-TRITC (Jackson ImmunoResearch Laboratories Inc.). Coverslips were mounted with Slowfade Light Antifade Kit (Invitrogen) and images captured with a fluorescence microscope by a Zeiss AxioCam HR camera using AxioVision software (Zeiss). For tissue staining, tissue was snap-frozen in OCT embedding compound (TissueTek; Sakura Finetek USA Inc.), and sections were cut and fixed as described above. Sections were quenched in $0.3 \% \mathrm{H}_{2} \mathrm{O}_{2} /$ methanol for 20 minutes and mouse tissue immunostained as described above, except that HRP-conjugated streptavidin (BD Biosciences - Pharmingen) and 3,3'-diaminobenzidine peroxidase substrate (Sigma-Aldrich) were used. Human turbinate tissue and nasal polyps were collected with informed consent and stained with anti-aP2 (clone 6E12) or anti-cytokeratin (Sigma-Aldrich) antibodies followed by HRP-conjugated goat anti-mouse Ig (Jackson ImmunoResearch Laboratories Inc.) antibodies. Slides were counterstained with Wright-Giemsa (Sigma-Aldrich).

Animals. aP2 $2^{-/-}$mice (40) were backcrossed for 12 generations to C57BL/6 mice (21) and used in airway inflammation studies. $a P 2^{+/+}$littermates or C57BL/6 mice from the Garvan Institute were used as controls. STAT6- ${ }^{--}$ mice were from the John Curtin School of Medical Research, Australian National University. BALB/c mice were purchased from Animal Resource Center (Perth, Western Australia, Australia) and used as controls for STAT6 ${ }^{-/}$ mice and other airway inflammation studies. Animals were housed under conventional barrier protection and experiments performed with approval of the Garvan Institute/St. Vincent's Hospital Animal Experimentation and Ethic Committee, which complies with the Australian National Health and Medical Research Council (NH\&MRC) code of practice for the care and use of animals for scientific purposes.

Mouse model of allergic airway inflammation. Mice (15-23 weeks of age in one experiment that assessed allergic inflammation in aP2-deficient mice and $8-10$ weeks in all other experiments) were sensitized by intraperitoneal injection of $100 \mu \mathrm{g}$ OVA (Sigma-Aldrich) or PBS adsorbed on $100 \mu \mathrm{l}$ alum (Progen) on days 0 and 14 . On days 28, 30, 32, and 33, mice were exposed to aeroallergen consisting of either 1\% OVA in PBS or PBS alone for 20 minutes. Mice were sacrificed on day 34, and after cannulation of the trachea, BAL was performed with $1 \mathrm{ml}$ PBS per mouse. Total cell counts were performed, and cytospin preparations of BAL cells were stained with modified Wright-Giemsa stain (Sigma-Aldrich) to permit differential leukocyte counts based on cellular morphology and staining characteristics. For lung histology, mouse lungs were fixed in $10 \%$ phosphate buffered formalin and embedded in paraffin. Sections were cut and stained with H\&E for general histology or with Alcian blue-PAS for evaluation of mucus production. The extent of the inflammatory response was graded in a blinded fashion as: 0 , minimal or no inflammation; 1 , mild inflammation, only perivascular or peribronchiolar; 2 , moderate inflammation, some parenchymal involvement; 3 , marked inflammation, widespread parenchymal involvement; 4 , severe inflammation, little normal parenchyma. The extent of mucous cell change in the largest visible airway was graded according to a semilogarithmic scale and is described elsewhere (56).

Bone marrow chimeras. Mice aged 5-7 weeks were irradiated with $9.50 \mathrm{~Gy}$ and 24 hours later reconstituted i.v. with $7 \times 10^{6}$ total bone marrow cells from $\mathrm{C} 57 \mathrm{BL} / 6$ or $a P 2^{-1-}$ mice. Allergic lung inflammation was induced in mice 6 weeks after engraftment with i.p. immunization of $100 \mu \mathrm{g}$ OVA in alum on day 0 and four 30-minute $1 \%$ OVA aeroallergen challenges on days 14, 16, 18, and 20. Allergic lung inflammation was assessed as described above. Hematopoietic cells from peripheral blood of chimeric mice were genotyped to ensure successful reconstitution of donor bone marrow (data not shown).

Mouse model of allergic peritonitis. Mice aged 6-8 weeks were immunized s.c. with $100 \mu \mathrm{g}$ OVA or PBS in alum on days 0 and 12 and challenged i.p. with $50 \mu \mathrm{g}$ OVA in $200 \mu \mathrm{l} \mathrm{PBS}$, or PBS only, every second day from day 24 . 
Twenty-four hours after the last challenge, mice were lavaged once with $1.5 \mathrm{ml}$ and then twice with $3 \mathrm{ml}$ ice-cold PBS. Cells from all lavages were pooled and prepared for cell counts as described above.

Lymph node cell culture and cytokine measurement. Lung-draining lymph nodes were pooled into groups, gently forced through a $70-\mu \mathrm{m}$ nylon cellstrainer, and resuspended in complete RPMI 1640. Cells were cultured at $4 \times 10^{5} \mathrm{cells} / \mathrm{ml}$ in 96 -well plates with 10,50 , or $100 \mu \mathrm{g}$ OVA per well for 72 hours and cell-free culture supernatants collected and stored at $-80^{\circ} \mathrm{C}$ until cytokine levels were assayed by ELISA according to the manufacturer's protocol: IL-5 (BD Biosciences - Pharmingen), IL-13 (PeproTech), and eotaxin (R\&D Systems).

$T$ cell proliferation assay. Mice were sensitized with OVA as per the bone marrow chimera allergic airway inflammation experiments and sacrificed on day 14 . The spleen was disaggregated through a $70-\mu \mathrm{M}$ nylon cell strainer and erythrocytes lysed. Splenocytes containing $1 \times 10^{5} \mathrm{~T}$ cells $/ 200 \mu \mathrm{l}$ were cultured in complete RPMI 1640 for 72 hours, with 10 or $50 \mu \mathrm{g}$ OVA. Cultures were pulsed with $\left[{ }^{3} \mathrm{H}\right]$ thymidine $(1 \mu \mathrm{Ci} /$ well $) 18$ hours before harvesting and quantified using a $\beta$-scintillation counter.

Statistics. For continuous data, 2-tailed Student's $t$ test was utilized, and $P<0.05$ was considered significant. Grading of histological changes was compared using a nonparametric Mann-Whitney $U$ test.

\section{Acknowledgments}

We thank J. Thatcher, L.G. Ng, T. So, and Z. Commandeur for technical assistance; P. Foster and M. Yang for discussion about the allergic inflammation model; R. Gallagher for human tissue; and the staff at the Garvan Institute Biological Testing Facility for animal care. This work was supported by grants from the Cooperative Research Centre for Asthma and Airways and the NH\&MRC of Australia (to C.R. Mackay and M.S. Rolph) and the Sandler Program of Asthma Research (to G.S. Hotamisligil).

Received for publication February 15, 2005, and accepted in revised form May 23, 2006.

Address correspondence to: Michael S. Rolph, Immunology and Inflammation, Research Program, The Garvan Institute of Medical Research, 384 Victoria Street, Sydney, New South Wales 2010, Australia. Phone: 61-2-9295-8531; Fax: 61-2-9295-8404; E-mail: m.rolph@garvan.org.au. Or to: Gökhan S. Hotamisligil, Harvard School of Public Health, 665 Huntington Avenue, Boston, Massachusetts 02115, USA. Phone: (617) 432-1950; Fax: (617) 432-1941; E-mail: ghotamis@hsph.harvard.edu.
1. Bochner, B.S., Undem, B.J., and Lichtenstein, L.M. 1994. Immunological aspects of allergic asthma. Annu. Rev. Immunol. 12:295-335.

2. Woolcock, A.J., Bastiampillai, S.A., Marks, G.B., and Keena, V.A. 2001. The burden of asthma in Australia. Med. J. Aust. 175:141-145.

3. Centers for Disease Control. 2002. Surveillance for asthma - United States, 1980-1999. MMWR Surveill. Summ. 51:1-13.

4. Strachan, D.P. 1989. Hay fever, hygiene, and household size. BMJ. 299:1259-1260.

5. Tattersfield, A.E., Knox, A.J., Britton, J.R., and Hall, I.P. 2002. Asthma. Lancet. 360:1313-1322.

6. Brusselle, G., Kips, J., Joos, G., Bluethmann, H., and Pauwels, R. 1995. Allergen-induced airway inflammation and bronchial responsiveness in wild-type and interleukin-4-deficient mice. Am. J. Respir. Cell Mol. Biol. 12:254-259.

7. Grunig, G., et al. 1998. Requirement for IL-13 independently of IL-4 in experimental asthma. Science. 282:2261-2263.

8. Shore, S.A. 2004. Direct effects of Th2 cytokines on airway smooth muscle. Curr. Opin. Pharmacol. 4:235-240.

9. Davies, D.E. 2001. The bronchial epithelium in chronic and severe asthma. Curr. Allergy Asthma Rep. 1:127-133.

10. Matsukura, S., et al. 2001. Interleukin-13 upregulates eotaxin expression in airway epithelial cells by a STAT6-dependent mechanism. Am. J. Respir. Cell Mol. Biol. 24:755-761.

11. Dabbagh, K., et al. 1999. IL-4 induces mucin gene expression and goblet cell metaplasia in vitro and in vivo. J. Immunol. 162:6233-6237.

12. Striz, I., et al. 1999. IL-4 induces ICAM-1 expression in human bronchial epithelial cells and potentiates TNF-alpha. Am. J. Physiol. 277:L58-L64.

13. Ponath, P.D., et al. 1996. Cloning of the human eosinophil chemoattractant, eotaxin. Expression, receptor binding, and functional properties suggest a mechanism for the selective recruitment of eosinophils. J. Clin. Invest. 97:604-612.

14. Rothenberg, M.E., Luster, A.D., and Leder, P. 1995. Murine eotaxin: an eosinophil chemoattractant inducible in endothelial cells and in interleukin 4-induced tumor suppression. Proc. Natl. Acad. Sci. U. S. A. 92:8960-8964.

15. Rolph, M.S., Sisavanh, M., Liu, S.M., and Mackay, C.R. 2006. Clues to asthma pathogenesis from microarray expression studies. Pharmacol. Ther.
109:284-294.

16. Jeffrey, K.L., et al. 2006. Positive regulation of immune cell function and inflammatory responses by phosphatase PAC-1. Nat. Immunol. 7:274-283.

17. Chtanova, T., et al. 2005. Identification of T cellrestricted genes, and signatures for different $\mathrm{T}$ cell responses, using a comprehensive collection of microarray datasets. J. Immunol. 175:7837-7847.

18. Liu, S.M., et al. 2006. "Immune cell transcriptome" datasets reveal novel leukocyte subset-specific genes, and genes associated with allergic processes. J. Allergy Clin. Immunol. In press.

19. Boord, J.B., et al. 2002. Adipocyte fatty acid-binding protein, aP2, alters late atherosclerotic lesion formation in severe hypercholesterolemia. Arterioscler. Thromb. Vasc. Biol. 22:1686-1691.

20. Makowski, L., et al. 2001. Lack of macrophage fattyacid-binding protein aP2 protects mice deficient in apolipoprotein E against atherosclerosis. Nat. Med. 7:699-705.

21. Scheja, L., et al. 1999. Altered insulin secretion associated with reduced lipolytic efficiency in aP2-/mice. Diabetes. 48:1987-1994.

22. Zimmerman, A.W., and Veerkamp, J.H. 2002. New insights into the structure and function of fatty acidbinding proteins. Cell. Mol. Life Sci. 59:1096-1116.

23. Hertzel, A.V., and Bernlohr, D.A. 2000. The mammalian fatty acid-binding protein multigene family: molecular and genetic insights into function. Trends Endocrinol. Metab. 11:175-180.

24. Makowski, L., and Hotamisligil, G.S. 2005. The role of fatty acid binding proteins in metabolic syndrome and atherosclerosis. Curr. Opin. Lipidol. 16:543-548.

25. Maeda, K., et al. 2003. Role of the fatty acid binding protein mal1 in obesity and insulin resistance. Diabetes. 52:300-307.

26. Tontonoz, P., Hu, E., Graves, R.A., Budavari, A.I., and Spiegelman, B.M. 1994. mPPAR gamma 2: tissue-specific regulator of an adipocyte enhancer. Genes Dev. 8:1224-1234.

27. Pelton, P.D., Zhou, L., Demarest, K.T., and Burris, T.P. 1999. PPARgamma activation induces the expression of the adipocyte fatty acid binding protein gene in human monocytes. Biochem. Biophys. Res. Commun. 261:456-458.

28. Chawla, A., et al. 2001. PPAR-gamma dependent and independent effects on macrophage-gene expression in lipid metabolism and inflammation. Nat. Med. 7:48-52.
29. Yu, S., et al. 2003. Adipocyte-specific gene expression and adipogenic steatosis in the mouse liver due to peroxisome proliferator-activated receptor gamma1 (PPARgamma1) overexpression. J. Biol. Chem. 278:498-505.

30. Kelly-Welch, A.E., Hanson, E.M., Boothby, M.R., and Keegan, A.D. 2003. Interleukin-4 and interleukin-13 signaling connections maps. Science. 300:1527-1528.

31. Kotanides, H., and Reich, N.C. 1996. Interleukin-4induced STAT 6 recognizes and activates a target site in the promoter of the interleukin-4 receptor gene. J. Biol. Chem. 271:25555-25561.

32. Matsukura, S., et al. 1999. Activation of eotaxin gene transcription by NF-kappa B and STAT6 in human airway epithelial cells. J. Immunol. 163:6876-6883.

33. Lee, J.H., et al. 2001. Interleukin-13 induces dramatically different transcriptional programs in three human airway cell types. Am. J. Respir. Cell Mol. Biol. 25:474-485.

34. Leung, D.Y., et al. 1995. Dysregulation of interleukin 4, interleukin 5, and interferon gamma gene expression in steroid-resistant asthma. J. Exp. Med. 181:33-40.

35. Shirakawa, T., Enomoto, T., Shimazu, S., and Hopkin, J.M. 1997. The inverse association between tuberculin responses and atopic disorder. Science. 275:77-79.

36. Zimmermann, N., et al. 2003. Dissection of experimental asthma with DNA microarray analysis identifies arginase in asthma pathogenesis. J. Clin. Invest. 111:1863-1874. doi:10.1172/JCI200317912.

37. Fulkerson, P.C., Zimmermann, N., Hassman, L.M., Finkelman, F.D., and Rothenberg, M.E. 2004. Pulmonary chemokine expression is coordinately regulated by STAT1, STAT6, and IFN-gamma. J. Immunol. 173:7565-7574.

38. Welch, J.S., Ricote, M., Akiyama, T.E., Gonzalez, F.J., and Glass, C.K. 2003. PPARgamma and PPARdelta negatively regulate specific subsets of lipopolysaccharide and IFN-gamma target genes in macrophages. Proc. Natl. Acad. Sci. U. S. A. 100:6712-6717.

39. Makowski, L., and Hotamisligil, G.S. 2004. Fatty acid binding proteins - the evolutionary crossroads of inflammatory and metabolic responses. J. Nutr. 134:2464S-2468S.

40. Hotamisligil, G.S., et al. 1996. Uncoupling of obesity from insulin resistance through a targeted mutation in aP2, the adipocyte fatty acid binding 
protein. Science. 274:1377-1379.

41. Hertzel, A.V., and Bernlohr, D.A. 1998. Regulation of adipocyte gene expression by polyunsaturated fatty acids. Mol. Cell. Biochem. 188:33-39.

42. Kuperman, D.A., et al. 2002. Direct effects of interleukin-13 on epithelial cells cause airway hyperreactivity and mucus overproduction in asthma. Nat. Med. 8:885-889.

43. Zimmermann, N., Hershey, G.K., Foster, P.S., and Rothenberg, M.E. 2003. Chemokines in asthma: cooperative interaction between chemokines and IL-13. J. Allergy Clin. Immunol. 111:227-242; quiz 243.

44. Makowski, L., Brittingham, K.C., Reynolds, J.M., Suttles, J., and Hotamisligil, G.S. 2005. The fatty acid-binding protein, aP2, coordinates macrophage cholesterol trafficking and inflammatory activity. Macrophage expression of aP2 impacts peroxisome proliferator-activated receptor gamma and IkappaB kinase activities. J. Biol. Chem. 280:12888-12895.

45. Helledie, T., et al. 2000. Lipid-binding proteins modulate ligand-dependent trans-activation by peroxisome proliferator-activated receptors and localize to the nucleus as well as the cytoplasm. J. Lipid Res. 41:1740-1751.

46. Veerkamp, J.H., van Moerkerk, H.T., Prinsen, C.F., and van Kuppevelt, T.H. 1999. Structural and functional studies on different human FABP types. Mol. Cell. Biochem. 192:137-142.

47. Zimmer, J.S., Dyckes, D.F., Bernlohr, D.A., and Murphy, R.C. 2004. Fatty acid binding proteins stabilize leukotriene A4: competition with arachidonic acid but not other lipoxygenase products. J. Lipid Res. 45:2138-2144.

48. Mehrabian, M., et al. 2002. Identification of 5 lipoxygenase as a major gene contributing to atherosclerosis susceptibility in mice. Circ. Res. 91:120-126.

49. Dwyer, J.H., et al. 2004. Arachidonate 5-lipoxygenase promoter genotype, dietary arachidonic acid, and atherosclerosis. N. Engl. J. Med. 350:29-37.

50. De Caterina, R., and Zampolli, A. 2004. From asthma to atherosclerosis - 5-lipoxygenase, leukotrienes, and inflammation. N. Engl. J. Med. 350:4-7.

51. Serhan, C.N., Takano, T., Chiang, N., Gronert, K., and Clish, C.B. 2000. Formation of endogenous "antiinflammatory" lipid mediators by transcellular biosynthesis. Lipoxins and aspirin-triggered lipoxins inhibit neutrophil recruitment and vascular permeability. Am. J. Respir. Crit. Care Med. 161:S95-S101.

52. Davidson, D.J., Kilanowski, F.M., Randell, S.H.,
Sheppard, D.N., and Dorin, J.R. 2000. A primary culture model of differentiated murine tracheal epithelium. Am. J. Physiol. Lung Cell Mol. Physiol. 279:L766-L778.

53. Chtanova, T., Kemp, R.A., Sutherland, A.P., Ronchese, F., and Mackay, C.R. 2001. Gene microarrays reveal extensive differential gene expression in both CD4(+) and CD8(+) type 1 and type 2 T cells. J. Immunol. 167:3057-3063.

54. Rozen, S., and Skaletsky, H.J. 2000. Primer3 on the WWW for general users and for biologist programmers. In Bioinformatics methods and protocols: methods in molecularbiology. S. Misener and S.A. Krawetz, editors. Humana Press. Totowa, New Jersey, USA. 365-386.

55. Yokoyama, WM. 1995. Production of monoclonal antibodies. In Current protocols in immunology. J.E. Coligan, A.M. Kruisbeek, D.H. Margulies, E.M. Shevach, and W. Strober, editors. John Wiley and Sons. New York, New York, USA. 2.5.1-2.5.17.

56. Temelkovski, J., Hogan, S.P., Shepherd, D.P., Foster, P.S., and Kumar, R.K. 1998. An improved murine model of asthma: selective airway inflammation, epithelial lesions and increased methacholine responsiveness following chronic exposure to aerosolized allergen. Thorax. 53:849-856. 